\title{
ANALISIS SURVEY FAKTOR-FAKTOR YANG MEMPENGARUHI TINDAK PIDANA KORUPSI APARAT PEMERINTAH DAERAH DAN PENCEGAHANNYA DI PROVINSI JAWA TENGAH
}

\begin{abstract}
This study aims to identify the effectiveness and efficiency of the implementation of good governance based on information technology (e-Governance) in the Central Java provincial government. It is intended that the corruption done by government officials could be prevented/avoided. To achieve this goal it is necessary to identify the existing conditions and constraints that arise both from internal and external factors that may impede the implementation of this system. The population in this study is all whole Unit of SKPD in Central Java Provincial Government with the unit of analysis the Head of SKPD. In this study, the samples are taken by using proportional random sampling.

The results of discussion on the study of corruption and e-governance conclude that the types of state capture, influence and administrative corruption can happen anytime and anywhere. Yet, the biggest concern of the corruption by government officials is administrative corruption. To prevent the corruption of local governments, it should implement the use of e-governance or the application of information technology to support the implementation of good-governance systems. However, the most important thing is the commitment of all officials in local government.
\end{abstract}

Keywords: E-governance, state capture, influence, administrative corruption

\section{PENDAHULUAN}

Indonesia saat ini telah menduduki posisi bagian atas di dunia dalam hal korupsi. Banyak kasus korupsi yang terjadi di negeri ini, bahkan banyak pakar yang menyebut sebagai negeri koruptor. Korupsi di Indonesia telah menjadi benang kusut dan terajut di hampir seluruh sisi dan tingkat kehidupan, mulai dari tingkat Rukun Tetangga (RT) hingga kelurahan. Selain merambah tingkat paling rendah, korupsi juga menjangkiti birokrasi seperti lembaga perwakilan rakyat, lembaga militer, dunia usaha, perbankan, dunia pendidikan, lembaga keagamaan, bahkan lembaga yang bertugas memberantas korupsi seperti kepolisian, kehakiman dan kejaksaan. (Muzadi, 2006:7).

Hasil Indeks Persepsi Korupsi (IPK) tahun 2007 yang diluncurkan oleh Transparancy Internasional, menunjukkan bahwa Indonesia berada diurutan 143 dengan nilai 2,3. Dengan nilai IPK itu, Indonesia termasuk negara terkorup di dunia bersama-sama 71 negara lainnya yang nilai skornya kurang dari 3. Selain itu, data dari Indonesia Corruption Watch (ICW) menyebut bahwa ditahun 2007 telah terjadi peningkatan kasus korupsi dibanding tahun lalu, yaitu sekitar 161 kasus dengan kebocoran mencapai Rp. 14,4 triliun (Transparency International 2007:2). Hal ini tentu saja akan berdampak pada pandangan negara lain terhadap indonesia yang akan membawa multiplier efek dari segala aspek.

Menurut Bung Hatta seperti yang dikutip oleh Masdar Hilmy, di era Orde Baru korupsi di Indonesia telah 
membudaya. Korupsi telah menjadi budaya yang melekat dihati. Masyarakat menjadi bangga dan asyik dengan korupsi. Otonomi daerah yang tujuan awalnya untuk memeratakan dan memajukan penduduk justru berimbas ke semakin meratanya korupsi di daerah (Tarmizi Taher 2005:109) Meskipun Indonesia terkenal sebagai negara yang agamis, namun menurut Azyumardi (2004), rendah dan tingginya korupsi tidak berhubungan dengan agama, tetapi berkaitan dengan tatanan hukum yang tegas dan dibarengi dengan penegakan hukum yang keras terhadap pelaku koruptor.

Jawa Tengah, salah satu provinsi di Indonesia juga tidak luput dari masalah korupsi. Menurut penggiat antikorupsi di Semarang, Komite Penyelidikan dan Pemberantasan Korupsi Kolusi dan Nepotisme (KP2KKN) Jawa Tengah mencatat selama tahun 2012 ada 215 kasus dugaan korupsi yang tersebar di 35 kabupaten/ kota di Jawa Tengah. Jumlah kasus korupsi yang terungkap itu, naik lebih dari 100 persen dibanding kasus yang terungkap di 2011, yakni sebanyak 102 kasus korupsi. (Tempo.com, Des 2012). KP2KKN hanya berhasil menghitung kerugian keuangan negara 71 persen dari 215 kasus itu. Dari 71 persen itu, terdapat kerugian negara sebesar Rp 381 miliar.

Sebagai warga Jawa Tengah, maka tergeraklah hati ini untuk melakukan penelitian tentang korupsi yang terjadi di Jawa Tengah serta berharap dapat menemukan model pencegahannya. Kemudian model yang kami temukan dapat dijadikan rujukan bagi provinsi lain. Penelitian ini lebih mengarah menganai faktor sistem itu sendiri dan faktor manusia yang dianggap dapat memberikan kesempatan bagi aparat pemerintahan melakukan korupsi.

Lopa(1997) mengatakan ada beberapa penyebab terjadinya korupsi. Semula disebabkan karena kondisi sosial ekonomi yang lemah sehingga seseorang melakukan tindakan korupsi dengan motivasi untuk mempertahankan hidup, namun kini telah bergeser ingin memperoleh kemewahan hidup. Teori tentang fraud (korupsi) juga dikemukakan oleh seorang kriminolog yaitu Donald Ray Cressey. Cressey(1950) menulis bahwa faktor-faktor yang menyebabkan orang melakukan fraud (kecurangan keuangan) ada 3(tiga), yaitu : Motivation (Pressure); Opportunity; dan Rationalization.

Sistem yang baik tentu akan berdampak pada kinerja yang baik. Salah satu sistem yang telah diterapkan baik diperusahaan maupun di organisasi publik lainnya di berbagai negara adalah sistem Good Governance. Sistem tata kelola yang baik inilah yang diharapkan akan dapat mengurangi tindakan korupsi oleh para aparat pemerintahan. Wilopo (2006) berpendapat bahwa untuk mencegah dan menghilangkan praktek kecurangan dapat dilakukan dengan beberapa cara, antara lain : pertama, mengefektifkan pengendalian internal, termasuk penegakan hukum. Kedua, perbaikan sistem pengawasan dan pengendalian. Ketiga, pelaksanaan good governance, dan keempat, memperbaiki moral dari pengelola yang diwujudkan dengan mengembangkan sikap komitmen terhadap perusahaan, negara dan masyarakat.

Teknologi Informasi telah diyakini mampu untuk mencegah ataupun mengurangi tindakan korupsi. Hal ini dibuktikan dengan banyak penelitian-penelitian tentang e-government yang memberikan hasil bahwa e-government dapat mengurangi ataupun mencegah tindakan korupsi yang dilakukan oleh aparat pemerintah. Cho dan Choi (2004) membangun proyek e-government yang disebut 'OPEN' (prosedur secara online peningkatan Layanan Pemerintah Metropolitan di Seoul untuk aplikasi sipil), proyek ini berhasil 
mengendalikan korupsi. Demikian juga Bhatnagar (2004); Csáki dan Gelléri (2005); Pathak dan Prasad (2006); dan Bhatnagar, Rao, Singh, Vaidya, dan Mandal (2007) membuktikan hal yang sama bahwa e-government dapat mengurangi korupsi.

\section{TELAAH LITERATUR DAN PENGEMBANGAN HIPOTESIS}

\section{E-Governance}

E-governance melebihi ruang lingkup e-government. Jika e-government didefi-nisikan sebagai penyampaian layanan pemerintah dan informasi kepada publik menggunakan sarana elektronik, e-governance memungkinkan partisipasi langsung dari konstituen di dalam aktivitas pemerintahan. Blake Haris menyimpulkan e-governance sebagai berikut :"E-governance is not just about government web site and e-mail. It is not just about service delivery over the Internet. It is not just about digital access to government information or electronic payments. It will change how citizens relate to governments as much as it changes how citizens relate to each other. It will bring forth new concepts of citizenship, both in terms of needs and responsibilities".

E-governance memungkinkan warga negara berkomunikasi antar-mereka maupun dengan pemerintah, dan berpatisipasi dalam proses pembuatan keputusan, mengeks-presikan kebututuhan nyata mereka tentang kesejahteraan dengan menggunakan e-government sebagai sarananya (means).

Berkenaan dengan e-governance, ada dua pertanyaan mendasar yang perlu mendapat jawaban tuntas. Pertama, bagaimana menetapkan kriteria good governance untuk pemanfaatan TI itu sendiri, dan kedua, bagaimana menempatkan posisi TI dalam upaya pencapaian good governance dari suatu organisasi, yang ditandai dengan adanya transparansi, akuntabilitas, adil (fair), efektif, dan dapat mengakomodasi partisipasi seluruh warga masyarakat.

Sejatinya, antara TI dan good governance saling mendukung. TI yang dikelola dengan baik - yang secara fisik dapat diakses, dengan biaya terjangkau, dan tanggap terhadap kebutuhan manusia - pada gilirannya akan mempercepat pembangunan nasional menjadi lebih demokratis, berkelanjutan (sustainable), dan memfasilitasi tercapainya masyarakat yang lebih sejahtera. Beberapa negara maju dan negara sedang membangun memberi contoh bagaimana upaya good governance selalu memasukkan unsur kebijakan di bidang hukum, dan keuangan yang mendorong kelompok wirausaha untuk melakukan inovasi dan penemuan baru yang mengarah pada terbentuknya perusahaan. Lingkungan yang dapat mempercepat layanan publik di bidang pendirian perusahaan, dan memu-dahkan usaha kecil menengah memperoleh kredit permodalan, adalah lingkungan yang mampu mendorong kalangan bisnis memperkenalkan teknologi baru ke masyarakat.

Pada akhirnya sasarannya adalah bagaimana membuat agar lebih banyak orang dapat memanfaatkan $\mathrm{Tl}$, sehingga Tl dapat mendorong terjadinya transformasi sosial dan ekonomi. Dengan demikian ungkaoan yang lebih tepat adalah "good governance dalam memanfaatkan $\mathrm{Tl}$, dan $\mathrm{TI}$ untuk mendukung upaya good governance."

Implementasi TI Untuk Mendukung Good Governance dan pencegahan korupsi.

Beberapa negara telah membuktikan keberhasilan mereka dalam memanfaatkan TI untuk mendukung 
good governance dan pencegahan korupsi. Di Korea, E-Governance digunakan sebagai tool untuk Anti Korupsi (Iqbal and Seo 2008). Korea membangun Proyek Seoul Metropolitan Government's 'OPEN' (Online Procedures ENhancement for civil applications); dan Korea's Government e-Procurement System (GePS). Kedua proyek tersebut sebagai "anti-corruption tool". Hasilnya menunjukkan bahwa e-governance sebagai tool yang efektif dalam memerangi korupsi.

Di Bangladesh (Iqbal,2010), e-governance telah dibuktikan sebagai tool anti korupsi yang efektif. Demikian juga Thailand (Rotchanakitumnuai, 2013), e-governance melalui aplikasi e-government procurement(E-GP) berhasil mengurangi korupsi, meskipun tidak berani menjamin akan lenyapnya korupsi. Di India (Pathak dan Prasad,2006), e-governance tidak hanya mengurangi korupsi, tetapi juga menaikkan pendapatan pemerintah yang dapat digunakan untuk kepentingan sosial seperti kesehatan, pendidikan dan memberantas kemiskinan. Negara Fiji dan Ethiopia juga menggunakan e-governance untuk mengurangi korupsi (Pathak, Singh, Belwal, Nas, dan Smith, 2007). Hasil riset di negeri tersebut menunjukkan bahwa e-governance berkorelasi positif dengan meningkatnya hubungan antara pemerintah dan warga negaranya serta dapat mengurangi korupsi.

Di Indonesia, e-governance telah dimulai sejak dikeluarkannya Instruksi Presiden No. 3/2003 tentang Kebijakan dan Strategi Nasional Pengembangan E-Government. Transparansi merupakan salah satu azas yang harus dipenuhi demi terwujudnya Good Public Governance (KNKG,2010). Sejalan dengan itu, Undang-undang Nomor 14 tahun 2008 tentang Keterbukaan Informasi Publik menyatakan bahwa informasi publik hendaknya disampaikan dengan cara yang mudah dijangkau oleh masyarakat. Menurut Styles dan Tennyson (2007), internet merupakan merupakan media yang paling mudah dijangkau oleh masyarakat dan dengan biaya yang paling efektif untuk menyebarkan informasi bagi pemerintah. Hermana et al. (2012) berhasil mengakses dan menganalisis 424 website Pemda seluruh indonesia pada bulan juni tahun 2011. Hasil pengamatan tersebut terlihat adanya trend kenaikan jumlah website Pemda yang bisa diakses oleh publik. Martani et al.(2013) mencatat dari 439 Pemda tingkat dua, hanya 429 website website yang dapat diakses dan diamati sepanjang pertengahan bulan Mei sampai akhir Juli 2013.

\section{METODE PENELITIAN}

\section{Populasi dan Sampel}

Populasi dalam penelitian ini seluruh pemerintah daerah yang ada di provinsi jawa tengah. unit analisis dalam penelitian ini adalah kepala SKPD sebagai pengambil kebijakan. Sampel yang dipilih dengan menggunakan metode proporsonal random sampling. Adapun tekniknya dengan memilih empat pemerintah daerah yang mewakili posisi wilayah pemerintah daerah. Keempat daerah tersebut terdiri dari provinsi jawa tengah wilayah Tengah/Pusat, wilayah Selatan, wilayah Barat, dan wilayah Timur. Namun dalam penelitian ini masing-masing pusat pertanggungjawaban harus terwakili mulai dari pusat pendapatan, pusta biaya, pusat investasi dan pusat laba.

\section{Definisi Operasional dan Pengukuran variabel.}

Dalam penelitian ini terdapat dua variabel independen yaitu variabel e-governance, dan satu variabel 
dependent yaitu korupsi. Berikut ini adalah definisi operasional masing-masing variabel dan pengukurannya :

\section{E-Good Governance}

E-Good governance adalah penyampaian layanan pemerintah dan informasi kepada publik menggunakan sarana elektronik, e-governance memungkinkan partisipasi langsung dari konstituen di dalam aktivitas pemerintahan. Variabel ini diukur dengan dengan 3 dimensi, yaitu keadilan, transparansi dan Pengendalian Internal.

\section{Korupsi}

Korupsi dibagi menjadi tiga jenis yaitu state capture, influence corruption dan administrative corruption. State capture adalah jenis korupsi dimana pihak kedua ikut mengambil bagian di dalam aturan main di dalam suatu sistem pemerintahan secara ilegal (seperti hukum, keputusan, aturan undang-undang) dengan melakukan pembayaran secara tidak transparan kepada pejabat publik. Influence corruption adalah kapasitas pihak kedua untuk mempengaruhi pengambil keputusan dalam bidang hukum dan undang-undang dengan melakukan pembayaran yang tidak transparan seperti suap atau lainnya. Administrative corruption adalah pembayaran oleh pihak kedua kepada pejabat publik untuk melancarkan kepentingannya (Joel, et.all, 2000).

\section{Disain Penelitian}

Disain penelitian ini adalah bersifat deskriptif kualitatif dengan memilih "human" sebagai sumber data, melakukan pengumpulan data, menilai kualitas data dan membuat kesimpulan atas temuannya (Sugiono, 2009). Wawancara kami lakukan untuk bertukar informasi dan ide melalui tanya jawab sehingga dapat dikonfirmasikan makna dalam suatu topik tertentu (Sugiono, 2009)

\section{HASIL DAN PEMBAHASAN}

\section{Kajian Tentang Korupsi}

Kajian untuk Korupsi ini dibagi menjadi tiga jenis yaitu state capture, influence corruption dan administrative corruption. Berdasarkan hasil survey dan wawancara langsung dengan responden kami mencoba untuk memetakan kajian korupsi ini dalam tabel 2.Korupsi jenis state capture ini sifatnya jarang terjadi. Jika diprosentasekan responden menjawab jarang terjadi $20 \%$ dan tidak pernah terjadi $80 \%$. Hal ini menunjukan bahwa korupsi ini meskipun pernah terjadi namun perjalanan waktu lima tahun terakhir ini frekuensinya sedikit. Untuk korupsi jenis influence corruption ini berdasarkan hasil wawancara diperoleh hasil dimana 50\% responden menjawab sering terjadi sedangkan yang jarang terjadi $45 \%$ dan tidak pernah terjadi 5\%. Sedangkan untuk korupsi jenis Administrative berdasarkan hasil wawancara diperoleh hasil dimana 80\% responden menjawab sering terjadi sedangkan yang jarang terjadi $20 \%$ dan tidak pernah terjadi $0 \%$. Jadi dapat disimpulkan bahwa korupsi yang sering terjadi di provinsi jawa tengah mayoritas korupsi jenis administrative, dimana ada pihak kedua atau pihak luar yang dengan sengaja memberikan pembayaran kepada pejabat publik untuk melancarkan urusannya dengan pemerintah daerah. 


\section{Kajian Teknologi informasi}

Peranan teknologi informasi bagi pemerintah sangat penting dalam hal pencegahan korupsi. Sistem Teknologi meskipun hanya sekedar alat atau media untuk mencapai tujuan organisasi secara lebih cepat dan lebih mudah, teknologi informasi ini mampu meminimalisasi kemungkinan korupsi yang terjadi. Pembayaran pajak atau retribusi atau biaya administrasi pelayanan publik yang secara online akan menutup kemungkinan seseorang melakukan pencurian atau kecurangan, karena semua pembayaran akan masuk ke satu pintu kas yaitu kas daerah. Berapapun pembayaran dan jenis apapun pembayaran itu akan dapat diketahui secara transparan dan akuntable oleh semua pihak termasuk auditor dalam hal ini BPK, BPKP atau inspektorat.

Berdasarkan hasil survey di atas dapat disimpulkan bahwa pemakaian teknologi informasi telah banyak digunakan atau dimanfaatkan untuk mendukung kinerja Pemerintah daerah. Secara garis besar Pemerintah daerah merasakan peran dan kegunaan teknologi informasi tersebut untuk mempercepat dan mempermudah pencapaian tujuan. Misalnya : Komputer, Internet, dan perangkat lunak lain yang lebih canggih. Namun yang menjadi kendala dalam hal ini adalah kapasitas teknologi informasi itu sendiri dan kualitas sumber daya manusianya. Teknologi informasi yang dimiliki pemerintah daerah harus mampu mengakomodasi seluruh kebutuhan pengguna IT tersebut. Semakin besar kebutuhan penggunanya maka akan semakin besar pula kapasitas IT yang diperlukan. Berdasarkan hasil wawancara dengan beberapa responden teknologi infromasi yang ada selama ini belum mampu mengakomodasi seluruh kebutuhan SKPD. Sebagi contoh maish ada beberapa SKPD yang memakai komputer jenis lama dan tidka tersambung dengan internet.

Sumberdaya manusia yang dimiliki pemerintah daerah juga sagat mendukung kinerja teknologi informasi ini. Sebaik apapun teknologi informasi yang dimiliki oleh pemerinta daerah tetapi tidak didukung oleh sumber daya manusia yang kompeten maka kinerja TI tersebut tidak akan bisa maksimal. Berdasarkan hasil survey ada beberapa upaya yang ditempuh oleh pemerintah daerah untuk meninkatkan kualitas sumberdaya manusia sebagai contoh SKPD memberikan perlakuan khusus bagi pegawai IT dengan mengikutkan pelatihan atau kursus sesuai dengan bidangnya masing masing.

\section{Kajian Good Governance}

Berdasarkan hasil survey bahwa pemahaman mengenai good governance secara umum baik artinya semua SKPD memahami pentingnya penerapan good governance bagi pemeirntah daerah khususnya untuk mengurangi bahkan dapat mencegah korupsi di pemerintah daerah di provinsi jawa tengah. Pentingnya transaparansi, akuntabilitas, responsibility dan keadilan merupakan suatu kesepakatan semua SKPD untuk mendukungnya. Penerpan prinsip-prinsip ini harus selalu dijaga dan dijadikan pedoman oleh semua SKPD untuk menunjang kinerjanya. Meskipun sebagian besar SKPD telah mengenal dan menerapkan good governance atau sistem tata kelola dengan baik, namun yang terpenting dari semua itu adalah komitmen dari pemerintah daerah itu sendiri. Sebaik apapun sistem yang dimiliki oleh pemerintah daerah namun jika semua pihak tidka memiliki komitmen yang maksimal maka sistem itu tidak aakan berjalan. Sistem reward dan punishment harus diterapkan secara adil dan transparan. 


\section{SIMPULAN}

Berdasarkan hasil pembahasan tentang kajian korupsi, kajian teknologi informasi dan kajian good governance di atas maka dapat disimpulkan bahwa korupsi baik jenis state capture, influence corruption dan administrative corruption akan dapat terjadi kapanpun dan dimanapun. Namun yang terbesar yang menjadi perhatian aparat pemerintah adalah korupsi jenis administrative corruption. Untuk mencegah adanya korupsi tersebut pemerintah daerah harus menerapkan penggunaan e-governance atau penerapan teknologi informasi yang akan mendukung implementasi sistem tata kelola pemeirntah yang baik. Namun yang terpenting lagi adalah komitmen dari semua aparat di pemerintah daerah.

\section{DAFTAR PUSTAKA}

Agusty Ferdinand. 2000. Structural Equation Modelling Dalam Penelitian Manajemen. Badan Penerbit Universitas Diponegoro.

Aimee, F.,dan Carol E., 2004, Aligning Priorities In Local Budgeting Processes. Journal of Public Budgeting, Accounting \& Financial Management. Boca Raton Summer 2004 Vol. 16, Iss.2; pg 210, 18 pgs.

Azra, Azyumardi, 2004. "Agama dan Pemberantasan Korupsi" dalam membasmi Kanker Korupsi. Jakarta : Pusat Studi Agama dan Peradaban (PSAP) Muhammadiyah.

Bambang. 2008. Analisis Potensi Pajak Daerah di Kabupaten Semarang sebagai sumber Pendapatan Asli Daerah (PAD). Hasil Penelitian tidak dipublikasi

Bambang. 2009. Pengaruh Good Government Governence terhadap Kinerja Pelayanan Publik Kelurahan Ganuksari Semarang. JAI. Vol 1 Maret. Semarang

Blackburn dan Rosen. 1993. Total Quality and Human Resources Management: lesson learned from Baldrige Award-winning companies; Academy of Management Executive, Vol 7 No.3

Bryman, A. 1990, Quantity and Quality in Social Science Reseach. London: Unwin/Heineman

Cho, Yong Hyo, and Choi, Byung-Dae 2004. E-Government to Combat Corruption:The Case of Seoul Metropolitan Government. International Journal of Public Administration, 27(10), 719-735.

Conger. J.A. \& Kanungo. R.N. 1988. The empowerment process: integrating theory and practice. Academic of Management Review, vol. 13. (3), 471-482.

Cressey, D.R. 1950, Criminal Violation of Financial Trust. PhDThesis, Indiana University, Department of Sociology. Cressey Donald R 1952 - Application and verification of the differential association theory. Journal of Criminal Law and Criminology. Vol 43. No.1. pp 43-52

Csáki, Csaba, and Gelléri, Péter 2005. Conditions and benefits of applying decision technological solutions as a tool to curb corruption within the procurement process: The case of Hungary. Journal of Purchasing \& Supply Management, 11(5-6), 252-259.

Dhammika, D., 2001, Legislative Bargaining and Incremental Budgeting. Economics Program Research School 
of Social Sciences. Australia National University Canberra, August 2001: 13-23

Edy, S. 2007. Pengaruh Good Governance terhadap Kinarja Perusahaan yang Listed di Bursa Efek Jakarta. Journal Akuntansi Indonesia Unissula, Maret. Semarang

Edy, S. 2008. Pengaruh penggunaan Teknologi Komputer dalam meningkatkan Kinerja Usaha Kecil di Kota Semarang. Jurnal Akunatnsi Indonesia. Juli . Semarang.

Edy \& Marno. 2010. Model Pemberdayaan Manajemen Sumber Daya Manusia Strategik, Teknologi Informasi, Dan Implementasi Good Governance Sebagai Nilai Tambah Dalam Meningkatkan Efektifitas Kinerja Program Nasional Pemberdayaan Masyarakat Mandiri (Pnpm) Mandiri Perkotaan Untuk Mengentaskan Kemiskinan. Hasil Penelitian Hibah Strategi Nasional. Semarang

Hofstede, Geert. 2011. Dimensionalizing Cultures:The Hofstede Model in Context. International Association for Cross-Cultural Psychology. Online Reading.

Indriati, Etty. 2014. Pola dan Akar Korupsi “Menghancurkan Lingkaran Setan Dosa Publik." PT Gramedia Pustaka Utama. Jakarta

Iqbal, M. Sohel, and Seo, Jin-Wan 2008. E-Governance as an anti-corruption tool: Korean Cases. Journal of Korean Association for Regional Information Society, 11(2), 51-78.

Iqbal, M. Sohel. 2010. Can E-governance hold back the Relationships between Stakeholders of Corruption? An Empirical Study of Developing Country. Journal of Economics and Business. Vol. XIII. No. 2 pp 83-106 Joel, et all. 2000. "Seize the state Seize the Day" state capture, corruption and influence in Transition. Policy Research Working Paper.

Kenis, I., 1979, Effects of Budgetary Goal Characteristics on Managerial Attitudes and Performance. The Accounting Review. LIV.2. Hal 707-721

Keputusan Menteri Dalam Negeri No. 29 Tahun 2002, Tentang Pedoman Pengurusan, Pertanggungjawaban dan Pengawasan Keuangan Daerah Serta Tata Cara Penyusunan APBD, Pelaksanaan Tata Usaha Keuangan Daerah dan Penyusunan Perhitungan APBD. Direktorat Pengelolaan Keuangan Daerah Direktorat Jenderal Otonomi Daerah, Jakarta

Komite Nasional Kebijakan Governance(KNKG). 2010. Pedoman Umum Good Public Governance.

Lopa, Baharuddin. 1997. Masalah Korupsi dan pemecahannya. Cetakan I. Jakarta: PT Kipas Putih Akasa

Marno Nugroho. 2005 .Pengaruh iklim Pembelajaran Organisasional terhadap perilaku menyimpang karyawan dengan Kepuasan kerja karyawan sebagai variabel moderasi Jurnal Riset dan Bisnis Indonesia. Vol 1 No 2. Juli , 137-148.

Marno Nugroho. 2008. Manajemen SDM Strategik suatu paradigma baru mengelola Perusahaan, Jurnal Riset dan Bisnis Indonesia. Vol 2 (Sep-Des) 35-47.

Michael, W. S. dan Troy A. 2000 Finacial Performance Monitoring And Custumer Oriented Government: A Case Study. Journal of Public Budgeting Accounting \&Financial Management, 12(1), 87-105

Muzadi, Hasyim. 2006. NU Melawan Korupsi “Kajian Tafsir dan Fiqh.” Cetakan I. Jakarta : Tim Kerja Gerakan Nasional Pemberantasan Korupsi. PBNU. 
Pathak, R. D., and Prasad, R. S. 2006. Role of E-governance in tackling corruption: The Indian Experience. In Raza Ahmad (Ed.), The role of public administration in building a harmonious society (p. 434-463). Philippines: Asian Development Bank.

Pathak, R.D., Singh, G., Belwal, R. and Smith, R.F.I. 2007. E-governance and Corruption developments and issues in Ethiopia. Public Organization Review, 7(3), 195-208. Critical Thinking in E-Governance 170

Peraturan Pemerintah Republik Indonesia Nomor 58 Tahun 2005 Tentang Pengelolaan Keuangan Daerah. Lembaga Negara Republik Indonesia Tahun 2005 Nomor 40

Raharjo, A., 2000, Pembekalan Teknis dan Manajemen Stratejik Teknik Pengganggaran/Keuangan Bagi Anggota DPRD dan Pejabat Pemda. PAU Studi Ekonomi UGM, Yogyakarta

Rotchanakitumnuai, Siriluck. 2013. The governance evidence of e-government procurement. Transforming Government: People, Process and Policy Vol. 7 No. 3, 2013 pp. 309-321

Spreitzer, GM. 1995. Psychological empowerment in the workplace: Dimension, measurement, and validation. Academy of Management Journal, 38 (5), 1442 - 1465.

Styles, Alan K., Mack Tennyson. 2007. The Accessibility of Financial Reporting U.S. Municipalities On The Internet. Journal of Public Budgeting, Accounting \& Financial Management, 19 (1) : 56-92

Sugiyono. 2009. Metode Penelitian Bisnis. Bandung : Alfabeta.

Wilopo. 2006. Analisis Faktor-faktor yang berpengaruh terhadap Kecenderungan Kecurangan Akuntansi. Studi pada Perusahaan Publik dan Badan Usaha Milik Negara. Publikasi SNA IX : Padang 


\section{Tabel 1}

Distribusi wilayah pemerintah daerah sample

\begin{tabular}{|c|c|c|}
\hline Nama Wilayah & Pemerintah Daerah Sampel & SKPD \\
\hline Tengah / Pusat & $\begin{array}{l}\text { Pemerintah kota Semarang dan Provinsi } \\
\text { Jawa Tengah }\end{array}$ & $\begin{array}{l}\text { - Dinas Pendapatan dan } \\
\text { Pengelolaan Aset Daerah } \\
\text { Provinsi } \\
\text { - Dinas Pendapatan dan } \\
\text { Pengelolaan Aset Daerah kota } \\
\text { Semarang. } \\
\text { - Dinas Tata Kota } \\
\text { - Dinas Pariwisata } \\
\text { - Dinas Pendidikan }\end{array}$ \\
\hline Selatan & Pemerintah kota Salatiga & $\begin{array}{l}\text { - Dinas Pendapatan dan } \\
\text { Pengelolaan Aset Daerah } \\
\text { - Dinas Kesbangpol }\end{array}$ \\
\hline Barat & Pemerintah kota Pekalongan & $\begin{array}{l}\text { - Dinas Pendapatan dan } \\
\text { Pengelolaan Aset Daerah } \\
\text { - Dinas Kesbangpol }\end{array}$ \\
\hline Timur & Pemerintah Kabupaten Demak & $\begin{array}{l}\text { - Dinas Pendapatan dan } \\
\text { Pengelolaan Aset Daerah } \\
\text { - Dinas Pekerjaan Umum } \\
\text { - Badan Kepegawaian Daerah } \\
\text { - Sekda }\end{array}$ \\
\hline
\end{tabular}

Tabel 2

Analisis Observasi Tentang Good Governance

\begin{tabular}{lccc}
\hline \multicolumn{1}{c}{ Keterangan } & $\begin{array}{c}\text { Sering } \\
\text { Terjadi }\end{array}$ & $\begin{array}{c}\text { Jarang } \\
\text { Terjadi }\end{array}$ & $\begin{array}{c}\text { Tidak } \\
\text { Pernah } \\
\text { Terjadi }\end{array}$ \\
\hline state capture & & $20 \%$ & $80 \%$ \\
\hline influence corruption & $50 \%$ & $45 \%$ & $5 \%$ \\
\hline administrative corruption & $80 \%$ & $20 \%$ & \\
\hline
\end{tabular}

Sumber : data primer yang diolah (2015) 